\title{
The influence of finfish aquaculture on benthic fish and crustacean assemblages in Fitzgerald Bay, South Australia
}

Jason E Tanner, Kane Williams

The influence of sea-cage aquaculture on wildfish assemblages has received little attention outside of Europe. Sea-cage aquaculture of finfish is a major focus in South Australia, and while the main species farmed is southern bluefin tuna (Thunnus maccoyii), there is also an important yellowtail kingfish (Seriola lalandi) industry. Yellowtail kingfish aquaculture did not appear to have any local or regional effects on demersal assemblages (primarily fish, but also some crustaceans) surveyed by baited remote underwater video (BRUV) in Fitzgerald Bay. We did, however, detect small scale spatial variations in assemblages within the bay. The type of bait used strongly influenced the assemblage recorded, with significantly greater numbers of fish attracted to deployments where sardines were used as the bait to compared to those with no bait. The pelleted feed used by the aquaculture industry was just as attractive as sardines at one site, and intermediate between sardines and no bait at the other. There was significant temporal variability in assemblages at both farm sites and one control site, while the second control site was temporally stable (over the 9 weeks of the study). Overall, the results suggested that aquaculture was having little if any impact on the abundance and assemblage structure of the demersal macrofauna in Fitzgerald Bay. 


\title{
1 The influence of finfish aquaculture on benthic fish and crustacean assemblages in
}

\section{Fitzgerald Bay, South Australia}

3

Jason E. Tanner ${ }^{1,2, \#}$ and Kane Williams ${ }^{1,2}$

${ }^{1}$ SARDI Aquatic Sciences, PO Box 120, Henley Beach, SA. Australia.

${ }^{2}$ School of Biological Sciences, University of Adelaide, SA. Australia.

\# Corresponding author

Phone: +61882075489

Email: jason.tanner@sa.gov.au

\begin{abstract}
The influence of sea-cage aquaculture on wildfish assemblages has received little attention outside of Europe. Sea-cage aquaculture of finfish is a major focus in South Australia, and while the main species farmed is southern bluefin tuna (Thunnus maccoyii), there is also an important yellowtail kingfish (Seriola lalandi) industry. Yellowtail kingfish aquaculture did not appear to have any local or regional effects on benthic fish and crustacean assemblages surveyed by downward pointing baited remote underwater video (BRUV) in Fitzgerald Bay. Significantly greater numbers of fish were attracted to deployments where sardines were used as the bait compared to those with no bait. The pelleted feed used by the aquaculture industry was just as attractive as sardines at one site, and intermediate between sardines and no bait at the other. There was significant temporal variability in assemblages at both farm sites and one control site over the 9 weeks of the study, and between northern and southern sites $\sim 3 \mathrm{~km}$ apart, suggesting that natural spatial and temporal variation was more important than feed inputs associated with aquaculture in structuring the surveyed assemblages. Overall, the results suggest that aquaculture was having little if any impact on the abundance and assemblage structure of benthic fish and crustaceans in Fitzgerald Bay.
\end{abstract}




\section{Introduction}

While global production figures are uncertain, it is clear that sea-cage aquaculture of finfish has expanded substantially in recent decades, due to increasing demand for seafood and largely steady production from wild capture fisheries (Halwart et al. 2007). As a consequence, there has been increased attention on its environmental effects. A range of biological and chemical aspects have been studied, including impacts associated with water column eutrophication, the benthic environment and assemblages, trophic structure and diseases or parasites (e.g. BayleSempere et al. 2013; Fernandes \& Tanner 2008; Kalantzi \& Karakassis 2006; Krkosek et al. 2007; Sara 2007a; Sara 2007b; Tanner \& Fernandes 2010). More recently, there has also been an increasing focus on the effects on wildfish assemblages in and around aquaculture lease areas (e.g. Dempster et al. 2002; Dempster et al. 2011; Fernandez-Jover et al. 2011; Ozgul \& Angel 2013; Uglem et al. 2014), although the major focus of this work has been in Europe, and especially the Mediterranean. Whether the conclusions derived from these studies are applicable across a broader geographic range is unclear. In Australia, a small amount of work has been done around a snapper farm on the east coast, which showed an increased abundance and biomass of wildfish compared to controls (Dempster et al. 2004), but the issue has received little detailed investigation.

The largely attractive effect of sea-cages that has been documented is assumed to be due to a combination of factors; habitat provision (Papoutsoglou et al. 1996), increased food availability (Pearson \& Black 2001; Uglem et al. 2014), and possibly chemical attraction to farmed stock (Dempster et al. 2002). Two years after abandonment, wildfish abundance around cages left in place at a fish farm in the Canary Islands had decreased 25-fold, although was still double that at controls (Tuya et al. 2006). This decrease was particularly evident in particulate organic matter feeders, but did not occur for herbivores or benthic macro- and meso-carnivores, suggesting that at least at this site, food availability (pellets) was the primary driver of changes, with habitat provision only playing a small role, although attraction to farmed stock cannot be discounted. The aggregation of wild fish has further environmental and ecological consequences that are poorly understood and vary between locations. Flow-on effects can include consumption of waste feed and faeces that would otherwise accumulate on the seafloor (Dempster et al. 2009; Felsing et al. 2005; Papoutsoglou et al. 1996), disease or parasite transfer (Krkosek et al. 2007), changes in local assemblage composition (Machias et al. 2005; Ozgul \& Angel 2013), and altered body condition and reproductive output (Dempster et al. 2011; Fernandez-Jover et al. 2011). If fishing is prohibited, aquaculture sites could function as marine sanctuary zones (Dempster et al. 2002), and enhance local stocks by both increasing reproductive output of wildfish due to increased feed availability (Edgar et al. 2014; Pelc et al. 2010) and providing emigrants to the surrounding environment (Roberts et al. 2001; Russ \& Alcala 2011). Alternatively, aquaculture leases may act as ecological traps (Gates \& Gysel 1978; Gilroy \& Sutherland 2007) if access to large quantities of aquaculture feed and faeces leads to decreases in condition and reproductive output of wildfish, although this appears not to be the case in Norway (Dempster et al. 2011). Where legislative protection from fishing is not afforded, aggregations around sea-cages may be easy targets for fishermen, which may exacerbate the over-exploitation of stocks (Dempster et al. 2004).

Here, we assess whether finfish aquaculture has affected the benthic fish and crustacean assemblages in Fitzgerald Bay, South Australia. The benthic assemblages were sampled by 
baited remote underwater video (BRUV) and compared on a local scale (between sites aquaculture vs no aquaculture) within Fitzgerald Bay, regional scale (with other nearby locations that do not contain finfish aquaculture) and over time to detect any differences attributable to aquaculture. We also test the influence of bait, and bait type, on the assemblages detected using BRUVs. While BRUV surveys typically target fish, they also allow other mobile fauna, such as decapod crustaceans, to be enumerated, and so we include both of these components of the benthic fauna.

During recent decades there has been a gradual shift towards the use of remote techniques to sample environments that are not accessible with traditional diver-conducted surveys, and now these methods are also being used in areas that were formerly sampled exclusively by divers (e.g. Lowry et al. 2012; Willis et al. 2000). The advantages of remote techniques stem from the fact that they are not subject to the limitations imposed upon divers by factors such as depth, temperature, time and safety requirements. The latter is of particular concern in this study, due to the frequent presence of great white sharks (Carcharodon carcharias) in the region. Many non-destructive remote techniques are ideally suited to sea-cage aquaculture and provide several inherent advantages over traditional diver surveys, as well as the universal benefits of remote techniques mentioned above. Non-destructive remote methods avoid the behavioural modifications induced in fish by the presence of divers (e.g. Cole et al. 2007; Watson et al. 2005), do not harm the species or the habitat sampled, and can provide information on the habitat and species behaviour (Harvey et al. 2013; Watson et al. 2005). Irrespective of technique, however, all surveys have their own biases that vary with habitat, environmental conditions and species being targeted. BRUV has become the standard non-destructive remote technique used for surveying demersal fish assemblages (McLean et al. 2011; Stobart et al. 2007; Unsworth et al. 2014), and is now also being used for pelagic assemblages (Santana-Garcon et al. 2014).

\section{Methods}

\section{Study area}

Fitzgerald Bay is located in northern Spencer Gulf, South Australia (Fig. 1). Sea-cage aquaculture was undertaken within the bay continuously from 1999 to 2010, initially producing snapper (Chrysophrys auratus) but since the early 2000's exclusively producing yellowtail kingfish (Seriola lalandi). At the time of this study in 2004, there were five 20 hectare lease sites (farms) in Fitzgerald Bay, four of which contained stock (all kingfish), with a combined annual production of approximately 620 tonnes. Production increased to 2000 tonnes per annum shortly after this study, but then declined steeply due to husbandry issues, and after 2010, it was relocated further south in Spencer Gulf. The farms containing fish were distributed along a channel that runs through Fitzgerald Bay, to the west of an offshore sandbank. The channel ranges in depth from 10-23 m and experiences substantial tidal flows (up to $39 \mathrm{~cm} \mathrm{sec}^{-1}$, (Parsons Brinckerhoff \& SARDI 2003)). Current direction is approximately north-south along the channel, alternating every six hours in a semi-diurnal pattern. The two farms chosen for the study were located at either end of the channel, to allow for the selection of suitable control sites (Fig. 1). Control sites were selected to be as similar as possible to each lease in terms of geographic location and water depth, and were at least one kilometre from any farm to minimise as much as possible impacts associated with aquaculture development. The southern lease and 
124 control sites were dominated by coarse substrate with numerous macroalgae and sponges, while 125 the northern sites had finer and mostly bare sediment, and there is a continuous narrow coastal 126 fringe of seagrass in shallower depths (less than 6 to $8 \mathrm{~m}$ : Hone et al. 1996; Shepherd 1974).

127 Further details on the site and production cycle can be found in Tanner \& Fernandes (2010).

\section{BRUV deployment}

Benthic BRUV was chosen as the survey technique. All sampling was undertaken during daylight hours $(0800-1700)$ using two BRUVs. Farm site deployments were made within $5 \mathrm{~m}$ of a sea-cage, and at least an hour after the single daily feeding had ceased at that cage. Feeding usually commenced early in the morning, but it could take several hours to complete feeding all the cages on a lease. Control sites were divided into 5 by 5 grids (i.e. 25 cells), cells were randomly chosen and BRUVs were deployed at their midpoint. Successive BRUV deployments were usually made 2-10 minutes apart, separated by a minimum distance of $200 \mathrm{~m}$, but as much as several kilometres depending upon the weather conditions. Once set, the boat was moved $>200 \mathrm{~m}$ away from the BRUVs and the motors turned off until retrieval.

Two Amphibico Dive Buddy housings were used with the BRUVs; one containing a Sony Digital Handycam DCR-TRV20E, the other a Sony Network Handycam DCR-TRV950E. Cameras were mounted vertically with a distance of $1 \mathrm{~m}$ between the lens and the seafloor. Deployment lengths of 30 minutes were chosen based on the early arrival times and low species numbers detected in the pilot study, where the maximum number of species (1-4) usually occurred before 20 minutes recording time had elapsed. Unless otherwise noted, a single small ( $\sim 400 \mathrm{~g})$ pack of frozen brined sardines (Sardinops sagax) was used as bait for each deployment. Prior to placement in a bait basket, sardines were thawed and crushed to maximise the bait plume.

BRUVs are considered as passive sampling tools, and do not require any ethics or other approvals in the jurisdiction in which this study was undertaken.

\section{Video analysis}

Video footage was viewed with a real-time counter, and analysis commenced from the moment that the BRUV settled on the seafloor. Relative abundance estimates of all mobile fauna were made by recording the maximum number of individuals of a single taxon visible within one frame of footage (MaxN, Ellis \& Demartini 1995). MaxN is a conservative measure of relative abundance because it usually underestimates the true numbers of each species visiting the bait (Cappo et al. 2004). Using MaxN avoids the problem of recounting the same individual on separate visits to the bait, and has been found to give an accurate estimate of "true" density (Willis et al. 2000). Due to difficulties with identifying small cryptobenthic fish species from the dorsal view recorded by the BRUVs, these species were grouped into a "benthic" category. The presence of two distinct cohorts of snapper (Chrysophrys auratus) in the surveys allowed separation of the classes for statistical analysis (juvenile $<38 \mathrm{~cm}$, adult $>38 \mathrm{~cm}$ ). Some blue swimmer crabs (Portunus armatus) were easily distinguished from others (e.g. male or female, missing claw, markings) and thus each new arrival in the FOV was included in the MaxN count regardless of whether they were all present in one frame of footage. 
170 Non-parametric permutational multivariate analysis of variance (PERMANOVA, Anderson 171 2001) was used to test for differences in assemblage composition between treatments. The Bray-

172 Curtis similarity was used for all analyses, with 9999 permutations of residuals under a reduced

173 model. All data were $4^{\text {th }}$ root transformed to downweight the influence of highly abundant

174 species, allowing both rare and common species to contribute to the analysis. Without this

175 transformation, the results would be determined almost entirely by the most abundant species (in

176 this case one taxon which had an order of magnitude greater abundance than others in some

177 components of the study) (Clarke \& Green 1988; Clarke \& Warwick 2001). Pair-wise $a$

178 posteriori comparisons were made for factors that were found to have a significant effect when

179 required. To visualise the similarities between samples, non-metric multi-dimensional scaling

180 (nMDS) ordination plots were used. A similar approach was taken to analyse Total MaxN (ie

181 the sum of MaxN across taxa), except that resemblances were calculated using Euclidean

182 distances and no transformation was applied. All analyses were conducted in Primer v6 with the

183 PERMANOVA+ add-on (Clarke \& Gorley 2006).

184

185 Local effects

186 To detect the local-scale effects of finfish aquaculture, BRUVs were used to survey the benthic

187 mobile fauna present on farm and control sites in Fitzgerald Bay. A three-way orthogonal

188 sampling design was used, with Proximity to Aquaculture (farm vs control), Location (north vs

189 south) and Tidal Phase (high vs low) as fixed factors, and three replicates. Sampling was

190 undertaken in late June 2004.

191

192

193 To determine if broader-scale regional impacts of aquaculture were present, the two Fitzgerald

194 Bay control sites were sampled once again, as were two 20 hectare sites both 28 kilometres to the

195 north (Douglas Point) and 22 kilometres to the south (Cowleds Landing) of Fitzgerald Bay (Fig.

196 1). Neither of these additional locations have been used for aquaculture. Sites within each

197 Location were positioned to match those in Fitzgerald Bay in terms of water depth, separation

198 and site dimensions (Fig. 1). A total of 36 deployments (6 sites x 6 replicates) were conducted

199

200 over three days in July 2004. Location was treated as a fixed factor, with Site nested in

201

202

203

204

205

206

207

208

209

210

211

212

213

214 Location.

\section{Bait effects}

To evaluate bait efficacy and the effect that different baits had on the sample composition of BRUV surveys in Fitzgerald Bay, three bait treatments were assessed: crushed sardines (as per previous surveys), extruded aquaculture pellets and a control without bait. Pellets used for daily feeding of yellowtail kingfish by the aquaculture industry in Fitzgerald Bay $(9 \mathrm{~mm}$ diameter, 9 $\mathrm{mm}$ long, $5.8 \%$ water content) were sourced directly from the aquaculture operators. The no bait treatment consisted of an empty bait basket. Sampling was undertaken throughout the day on three consecutive days in August-September 2004. Each bait treatment was applied to each of the two farm and two control sites from the first survey ( 3 baits $\times 4$ sites $\times 5$ replicates $=60$ deployments) following the protocols described under BRUV deployment, and in a random order. Strong tides during sampling resulted in the loss of six deployments from the southern sites. Bait Type (sardine vs pellet vs no bait), Proximity to Aquaculture (farm vs control), and Location (north vs south) were treated as fixed factors in a 3-way experimental design.

215 
217 To determine whether the effects of finfish aquaculture varied over time, and to examine the

218 temporal stability of the assemblages within Fitzgerald Bay, a temporal comparison of BRUV

219 samples from all three surveys was undertaken. This analysis involved all data from Fitzgerald Bay where sardines were used as the bait, and thus included three factors: Proximity to Aquaculture (farm vs control); Time (3 surveys) and Location (north vs south). As no data were collected from adjacent to cages for the regional comparison, there is an empty cell in this design, so the analysis was repeated without data from this comparison (ie with data from only 2 surveys). As the results were qualitatively similar, only the results for the analysis with 3 levels of Time are presented.

\section{Results}

The 114 BRUV deployments resulted in a total MaxN of 706 across 17 taxa. Over half of these individuals were carangids (Pseudocaranx wrighti-381), with 121 in the 'benthic' category, 68 snapper, 63 blue swimmer crabs, 28 western king prawns (Penaeus latisulcatus), 18 bridled leatherjackets (Acanthaluteres spilomelanurus), 10 Port Jackson sharks (Heterodontus portusjacksoni), 8 sand flathead (Platycephalus bassensis), and 1-2 individuals each of smalltooth flounder (Pseudorhombus jenynsii), three species of unidentified demersal fish, the holothurian Australostichopus mollis, red swimmer crab (Nectocarcinus integrifrons), southern calamary (Sepioteuthis australis) and the starfish Allostichaster polyplax. Full details of taxa recorded in each deployment are provided in the supplementary information.

\section{Local effects}

No local-scale effects of aquaculture were detected on the benthic fish and crustacean assemblages surveyed by BRUV in Fitzgerald Bay (PERMANOVA: $\mathrm{F}_{1,15}=0.55, \mathrm{P}=0.63$ ). There was a clear difference between north and south in the bay, however (PERMANOVA: $\mathrm{F}_{1,15}=13.95, \mathrm{P}<0.001$ ), with the northern area having high numbers of the western king prawn and carangids, while the southern area was dominated by blue swimmer crabs (Fig. 2, Table 1). Tidal Phase had no influence on the assemblage (PERMANOVA: $\mathrm{F}_{1,15}=1.22, \mathrm{P}=0.36$ ), and there were no interactions between any factors (all $\mathrm{P}>0.18$ ). No factor (or interaction) had a significant effect on TotalMaxN (all $\mathrm{P}>0.16$ ), with the mean value being $7.9 \pm 1.2(\mathrm{se})$.

\section{Regional effects}

No differences in assemblage structure (Table 2) were detected between the three locations (PERMANOVA: $\mathrm{F}_{2,3}=0.50, \mathrm{P}=0.93$ ), although there were significant differences between Sites within Locations (PERMANOVA: $\mathrm{F}_{3,30}=6.35, \mathrm{P}<0.001$ ). Similar results were obtained for TotalMaxN (PERMANOVA: $\mathrm{F}_{2,3}=0.37, \mathrm{P}=0.94$ and $\mathrm{F}_{3,30}=8.6, \mathrm{P}<0.001$ for Location and Site respectively, mean $\pm \mathrm{se}=3.7 \pm 0.5)$.

\section{Bait effects}

In the bait effects study, assemblage structure was influenced by interactions between Proximity to Aquaculture and both Bait Type and Location in bay (Table 3). Pairwise tests indicated that the south control site had a different assemblage to the other 3 sites $(\mathrm{P}<0.007)$. This site had high numbers of juvenile snapper and blue swimmer crabs in comparison to the other sites (Fig. 3 ). At the farm sites, deployments with bait differed from those without $(\mathrm{P}=0.002)$, but there was no difference between using sardines or aquaculture pellets $(\mathrm{P}=0.58)$. At the control sites, 
262

sardines differed from no bait $(\mathrm{P}=0.018)$, but pellets did not differ to either sardines $(\mathrm{P}=0.57)$ or no bait $(\mathrm{P}=0.2)$. Deployments with no bait attracted very few (or no) fauna ( 8 individuals in 16 deployments, 5 in the 'benthic' category, compared to 376 across 38 baited deployments; Table 4).

TotalMaxN was significantly affected by the interaction between Proximity, Location and Bait type (PERMANOVA: $\mathrm{F}_{2,42}=7.03, \mathrm{P}=0.003$; Table 4 ). Pairwise tests showed deployments with pellets at the south farm site attracted ten times the abundance of benthic fish and crustaceans as at the associated control site $(\mathrm{P}=0.008)$, and five times the abundance as at the northern farm site $(\mathrm{P}=0.009)$. At the north farm site, sardines attracted five times as many animals as pellets, and 150 times as many as unbaited deployments, while at the south farm site, pellets attracted three times as many as sardines, while unbaited deployments attracted no fauna.

\section{Temporal effects}

The temporal comparison again showed complicated interactions for assemblage structure (Table 5). Pairwise tests showed temporally variable assemblages at both farm sites (south: $\mathrm{P}=0.023$; north: $\mathrm{P}=0.011$ ), and for the north control site ( $\mathrm{P} \leq 0.011$ for all pairs of Time). Western king prawns were only present in the first survey, while the final survey documented high numbers of carangids and low numbers in the 'benthic' category. In contrast, the south control site was temporally stable $(\mathrm{P} \geq 0.18)$, with consistently high numbers of blue swimmer crabs, Port Jackson sharks and the 'benthic' category (Fig. 4).

For TotalMaxN, the interaction between Time, Proximity and Location was significant (PERMANOVA: $\mathrm{F}_{1,44}=4.5, \mathrm{P}=0.031$, see Tables $1,2 \& 4$ ). Importantly, pairwise tests showed that farm sites did not differ from control sites at each time and location. At the north farm site, there were three times as many fauna at the final census as at the first, while at the control site, the first and final census had four and six times as many fauna respectively as the intermediate census. During the intermediate survey, south control sites had more than three times the abundance as north control sites.

\section{Discussion}

\section{Effects of aquaculture}

The presence of finfish aquaculture was found to have no effect on the composition of the benthic fish and crustacean assemblages surveyed by BRUV in Fitzgerald Bay on a local or regional scale, although we did detect small-scale spatial and temporal variation in assemblages unrelated to aquaculture. This finding contrasts to most studies that have examined wildfish assemblages around aquaculture cages, which have shown altered community composition, and increased abundance and biomass, as a result of aquaculture (e.g. Dempster et al. 2005; Dempster et al. 2004; Dempster et al. 2002; Dempster et al. 2009; Giannoulaki et al. 2005; Ozgul $\&$ Angel 2013; Valle et al. 2007). Machias et al. $(2004,2005)$ also showed regional scale increases in wildfish abundance as a result of aquaculture due primarily to an increase in predators on benthic invertebrates and small fish (ie not species likely to feed directly on aquaculture waste). This general increase in fish abundance around farms appears to be method independent, with the studies mentioned above using techniques as varied as diver surveys, trawls, remote video and acoustic surveys, although none have used baited video as we did. 
308

309

310

311

312

313

314

315

316

317

318

319

320

321

322

323

324

325

326

327

328

329

330

331

332

333

334

335

336

337

338

339

340

341

342

343

344

345

346

347

348

349

350

351

352

353

While these studies primarily focused on pelagic assemblages directly associated with the cages, or included both pelagic and demersal assemblages, Bacher et al. (2012) explicitly examined benthic fish assemblages by diver survey at a farm in Spain and also found them to differ with proximity to cages.

The lack of response to aquaculture detected here may be due to the relatively small-scale nature of the industry in Fitzgerald Bay, which was still expanding at the time of this study, and/or the wide dispersal of wastes, both of which would limit the availability of aquaculture derived food. With an annual production in Fitzgerald Bay of 620 tonnes across four farms at the time of the study, and a food conversion ratio of $\sim 3: 1$ (Fernandes \& Tanner 2008), feed input was $\sim 1860$ tonnes year ${ }^{-1}$. This was sufficient to produce detectable effects on sediment organic carbon and porewater nutrient levels, but did not produce a clear effect on either infauna or epifauna (Tanner \& Fernandes 2010). Production in Fitzgerald Bay is at the low end of the range for the studies above that have reported impacts of aquaculture on wildfish assemblages (125-3000 tonnes for those that provided details), although none of these studies report total production for a region, instead only reporting production for individual farms. Now that yellowtail kingfish production is expanding again in South Australia, there is the potential for farming to resume at Fitzgerald Bay. The data presented here, and by Tanner \& Fernandes (2010), suggest that at similarly low levels, there would be minimal ecological impact. However, the risk of impacts would increase if production were to expand to typical commercially viable levels seen elsewhere in the world (i.e. several thousand tonnes per annum).

Given the substantial tidal flows through Fitzgerald Bay (up to $39.1 \mathrm{~cm} \mathrm{sec}^{-1}$, Parsons Brinckerhoff and SARDI 2003) and the seafloor clearance (5 to $15 \mathrm{~m}$ ) of the sea-cage nets, there is ample opportunity for waste dispersal to occur over a substantial area, especially for lightweight wastes (faeces). Conversely, pelleted feed sinks rapidly and is not carried far from the farm, although the accumulation of pellets underneath farms has not been seen (Tanner pers. obs.), and feed wastage appears to be limited (Fernandes \& Tanner 2008).

The combination of these factors may prevent sufficient waste deposition beneath the sea-cages in Fitzgerald Bay to attract resident demersal scavengers. Furthermore, during the bait effects study, pellets held in bait baskets were observed to disintegrate within the 30 minute duration of a BRUV deployment. Any pellets, therefore, that did reach the seafloor would most likely disintegrate rapidly and either be consumed by the resident demersal fauna or dispersed by the tide within a very short time. Such limited food availability would provide little direct incentive for scavengers to accumulate in the area.

If the scavengers most involved in waste mitigation in Fitzgerald Bay did not remain associated with the sea-cages for long periods, they may not have been sampled by the techniques used in this survey, as feeding times were avoided during sampling. Wild species have been observed to modify their behaviour in response to aquaculture practices. Sea birds follow feed boats from cage to cage and wild fish follow inter-tidal oyster farmers during infrastructure defouling (Williams pers. obs.). It is possible, therefore, that the scavengers in Fitzgerald Bay may also have modified their behaviour. Regardless of the cue (e.g. boat engines, the noise of pellets hitting the surface of the water, the feeding activity of farmed fish), the scavengers may have moved from cage to cage during feeding and thus were not observed in the BRUV deployments. Such movements are a distinct possibility for highly mobile species such as carangids, which 
354

355

356

357

358

359

360

361

362

363

364

365

366

367

368

369

370

371

372

373

374

375

376

377

378

379

380

381

382

383

384

385

386

387

388

389

390

391

392

393

394

395

396

397

398

399

were the most abundant species in this study. It is also possible that fish attracted by the presence of aquaculture remain tightly associated with the cages, and were not attracted to nearby BRUVs. Several attempts were made to survey such assemblages with various video deployments, but were unsuccessful, possibly due to limited ability to control which direction the camera pointed. In this respect, a camera allowing greater control, such as used by Dempster et al. (2009) may prove more successful.

\section{Bait effects}

While there were complex interactions in the bait effects study, deployments without bait clearly documented a different assemblage to those with bait. The low numbers of fauna documented in the former suggests that unbaited videos had no attractant effect, but rather simply recorded those animals that happened to pass through. That the use of bait increases the abundance and diversity of the fish assemblage recorded is well documented (e.g. Bernard \& Goetz 2012; Hardinge et al. 2013), although a detailed analysis of feeding guilds across a range of habitats showed that this attractant effect only held for predatory and scavenging species, and not for herbivores or omnivores (Harvey et al. 2007).

Sardines and pellets appeared equally effective as bait, at least in terms of assemblage composition. While sardines are the standard bait used for BRUV deployments in Australia, previous work has also shown that other bait types can be equally as effective when it comes to documenting assemblage composition (Dorman et al. 2012; Wraith et al. 2013). However, both of these studies did find differences between bait types on univariate measures such as total abundance.

\section{Temporal stability}

Dempster et al. $(2002,2004)$, found that wild fish aggregations associated with sea-cages in the Mediterranean were relatively temporally stable over periods ranging from several weeks to months. Bacher et al. (2012) found a similar result for benthic fish assemblages, but not midwater and surface, which varied with season. The benthic fish and crustacean assemblages in Fitzgerald Bay also varied over the course of the present study (nine weeks) at both lease sites and one of the control sites. This difference could be due to the fact that this study was essentially sampling natural communities, whereas the aggregations examined by Dempster et al. $(2002,2004)$ were not present prior to the establishment of aquaculture. The differences detected in the present study were possibly due to seasonality; with species responding to the transition from early (June) to late (August-September) winter.

While some species were detected throughout the present study (blue swimmer crabs, carangids, juvenile snapper, "Benthic" category), there were several interesting temporal trends for other species. Mature snapper, western king prawns, Port Jackson sharks and bridled leatherjackets were recorded exclusively during one sampling period. Very low individual counts and sporadic sightings of the latter two species prevent temporal inferences from being made from the existing data. Western king prawns, however, were common during the first survey (June) and absent from the third survey (August-September). Activity in this species is directly related to water temperature, with minimum activity occurring during the cooler winter months (King 1977). During August-September, water temperatures in Fitzgerald Bay can drop down to $\sim 13^{\circ} \mathrm{C}$ compared to maximum summer temperatures of $\sim 24^{\circ} \mathrm{C}$ (Parsons Brinckerhoff \& SARDI 2003). 
400 The lower limit of activity for penaeid prawns is $10-12^{\circ} \mathrm{C}$; therefore, most were likely to have 401 been buried in the sediment during the third survey (King 1977). The species is also migratory, 402 with individuals moving in a southerly and easterly direction as they mature (Carrick 1982) and 403 thus likely to leave Fitzgerald Bay during the year. Adult snapper were recorded only during the 404 second survey, which corresponds with the lead-up to their annual reproductive season in upper 405 406

\section{Conclusions}

Finfish aquaculture in Fitzgerald Bay does not appear to have affected the resident assemblage of benthic fish and crustaceans, as we did not detect any local or regional scale effects on these assemblages in BRUV surveys, despite finding natural small-scale spatial and temporal variation unrelated to aquaculture. Similarly, a concurrent study of other components of the ecosystem in Fitzgerald Bay, which showed detectable impacts on sediment chemistry, did not find effects on infaunal and epifaunal assemblages (Tanner \& Fernandes 2010). Together, these studies suggest that the benthic ecology within the bay is not being substantially affected by waste from the seacages. This finding contrasts with most previous work of a similar nature, which may be explained by the relatively low total aquaculture production in Fitzgerald Bay, and high rates of water movement.

\section{Acknowledgements}

The cooperation of South Australian Aquaculture Management (SAAM) during the field-work component of the project was greatly appreciated. We would like to thank I. Magraith, S. De Jong, N. Chigwidden and M. Ucinek for their invaluable assistance, and S. Bryars, M. Deveney and S. Madigan for advice. Two anonymous reviewers and M. Cotello provided valuable comments on earlier versions of the manuscript.

\section{References}

Anderson MJ. 2001. A new method for non-parametric multivariate analysis of variance. Austral Ecology 26:32-46.

Bacher K, Gordoa A, and Sagué O. 2012. Spatial and temporal extension of wild fish aggregations at Sparus aurata and Thunnus thynnus farms in the north-western Mediterranean. Aquaculture Environment Interactions 2:239-252.

Bayle-Sempere JT, Arreguin-Sanchez F, Sanchez-Jerez P, Salcido-Guevara LA, Fernandez-Jover D, and Zetina-Rejon MJ. 2013. Trophic structure and energy fluxes around a Mediterranean fish farm. Ecological Modelling 248:135-147.

Bernard ATF, and Goetz A. 2012. Bait increases the precision in count data from remote underwater video for most subtidal reef fish in the warm-temperate Agulhas bioregion. Marine Ecology Progress Series 471:235-252.

Cappo M, Speare P, and De'ath G. 2004. Comparison of baited remote underwater video stations (BRUVS) and prawn (shrimp) trawls for assessments of fish biodiversity in inter-reefal areas of the Great Barrier Reef Marine Park. Journal of Experimental Marine Biology and Ecology 302:123-152.

Carrick N. 1982. Spencer Gulf prawns. SAFIC Magazine 6:3-31.

Clarke KR, and Gorley RN. 2006. PRIMER v6: User manual/tutorial. Plymouth: PRIMER-E. 
446

447

448

449

450

451

452

453

454

455

456

457

458

459

460

461

462

463

464

465

466

467

468

469

470

471

472

473

474

475

476

477

478

479

480

481

482

483

484

485

486

487

488

489

490

Clarke KR, and Green RH. 1988. Statistical design and analysis for a biological effects study. Marine Ecology Progress Series 46:213-226.

Clarke KR, and Warwick RM. 2001. Change in marine communities: An approach to statistical analysis and interpretation. Plymouth: PRIMER-E Ltd.

Cole RG, Syms C, Davey NK, Gust N, Notman P, Stewart R, Radford CA, Carbines G, Carr $\mathrm{MH}$, and Jevs AG. 2007. Does breathing apparatus affect fish counts and observations? A comparison at three New Zealand fished and protected areas. Marine Biology 150:13791395.

Dempster T, Fernandez-Jover D, Sanchez-Jerez P, Tuya F, Bayle-Sempere J, Boyra A, and Haroun RJ. 2005. Vertical variability of wild fish assemblages around sea-cage fish farms: implications for management. Marine Ecology-Progress Series 304:15-29.

Dempster T, Sanchez-Jerez P, Bayle-Sempere J, and Kingsford M. 2004. Extensive aggregations of wild fish at coastal sea-cage fish farms. Hydrobiologia 525:245-248.

Dempster T, Sanchez-Jerez P, Bayle-Sempere JT, Gimenez-Casalduero F, and Valle C. 2002. Attraction of wild fish to sea-cage fish farms in the south-western Mediterranean Sea: spatial and short-term temporal variability. Marine Ecology-Progress Series 242:237252.

Dempster T, Sanchez-Jerez P, Fernandez-Jover D, Bayle-Sempere J, Nilsen R, Bjorn PA, and Uglem I. 2011. Proxy Measures of Fitness Suggest Coastal Fish Farms Can Act as Population Sources and Not Ecological Traps for Wild Gadoid Fish. PLoS ONE 6.

Dempster T, Uglem I, Sanchez-Jerez P, Fernandez-Jover D, Bayle-Sempere J, Nilsen R, and Bjorn PA. 2009. Coastal salmon farms attract large and persistent aggregations of wild fish: an ecosystem effect. Marine Ecology-Progress Series 385:1-14.

Dorman SR, Harvey ES, and Newman SJ. 2012. Bait Effects in Sampling Coral Reef Fish Assemblages with Stereo-BRUVs. PLoS ONE 7.

Edgar GJ, Stuart-Smith RD, Willis TJ, Kininmonth S, Baker SC, Banks S, Barrett NS, Becerro MA, Bernard ATF, Berkhout J, Buxton CD, Campbell SJ, Cooper AT, Davey M, Edgar SC, Foersterra G, Galvan DE, Irigoyen AJ, Kushner DJ, Moura R, Parnell PE, Shears NT, Soler G, Strain EMA, and Thomson RJ. 2014. Global conservation outcomes depend on marine protected areas with five key features. Nature 506:216-220.

Ellis DM, and Demartini EE. 1995. Evaluation of a video camera technique for indexing abundances of juvenile pink snapper, Pristipomoides filamentosus, and other Hawaiian insular shelf fishes. Fishery Bulletin 93:67-77.

Felsing M, Glencross B, and Telfer T. 2005. Preliminary study on the effects of exclusion of wild fauna from aquaculture cages in a shallow marine environment. Aquaculture 243:159-174.

Fernandes M, and Tanner JE. 2008. Modelling of nitrogen loads from the farming of yellowtail kingfish Seriola laiandi (Valenciennes, 1833). Aquaculture Research 39:1328-1338.

Fernandez-Jover D, Martinez-Rubio L, Sanchez-Jerez P, Bayle-Sempere JT, Lopez Jimenez JA, Martinez Lopez FJ, Bjrn PA, Uglem I, and Dempster T. 2011. Waste feed from coastal fish farms: a trophic subsidy with compositional side-effects for wild gadoids. Estuarine, Coastal and Shelf Science 91:559-568.

Fowler AJ, and Jennings PR. 2003. Dynamics in 0+ recruitment and early life history for snapper (Pagrus auratus, Sparidae) in South Australia. Marine and Freshwater Research 54:941956. 
491

492

493

494

495

496

497

498

499

500

501

502

503

504

505

506

507

508

509

510

511

512

513

514

515

516

517

518

519

520

521

522

523

524

525

526

527

528

529

530

531

532

533

534

535

Gates JE, and Gysel LW. 1978. Avian nest dispersion and fledging success in field-forest ecotones. Ecology 59:871-883.

Giannoulaki M, Machias A, Somarakis S, and Karakassis I. 2005. Wild fish spatial structure in response to presence of fish farms. Journal of the Marine Biological Association of the United Kingdom 85:1271-1277.

Gilroy JJ, and Sutherland WJ. 2007. Beyond ecological traps: perceptual errors and undervalued resources. Trends in Ecology \& Evolution 22:351-356.

Halwart M, Soto D, and Arthur JR. 2007. Cage aquaculture: Regional reviews and global overview. Rome: FAO. p 259.

Hardinge J, Harvey ES, Saunders BJ, and Newman SJ. 2013. A little bait goes a long way: The influence of bait quantity on a temperate fish assemblage sampled using stereo-BRUVs. Journal of Experimental Marine Biology and Ecology 449:250-260.

Harvey ES, Cappo M, Butler JJ, Hall N, and Kendrick GA. 2007. Bait attraction affects the performance of remote underwater video stations in assessment of demersal fish community structure. Marine Ecology Progress Series 350:245-254.

Harvey ES, Cappo M, Kendrick GA, and McLean DL. 2013. Coastal Fish Assemblages Reflect Geological and Oceanographic Gradients Within An Australian Zootone. PLoS ONE 8:e80955.

Hone P, Vandepeer M, Clarke S, and Nichols J. 1996. Fitzgerald Bay snapper aquaculture baseline environmental monitoring program Adelaide, South Australia: South Australian Research and Development Institute (Aquatic Sciences)

Kalantzi L, and Karakassis L. 2006. Benthic impacts of fish farming: Meta-analysis of community and geochemical data. Marine Pollution Bulletin 52:484-493.

King MG. 1977. The biology of the western king prawn Penaeus latisulcatus Kishinouye and aspects of the fishery in South Australia MSc. University of Adelaide.

Krkosek M, Ford JS, Morton A, Lele S, Myers RA, and Lewis MA. 2007. Declining wild salmon populations in relation to parasites from farm salmon. Science 318:1772-1775.

Lowry M, Folpp H, Gregson M, and Suthers I. 2012. Comparison of baited remote underwater video (BRUV) and underwater visual census (UVC) for assessment of artificial reefs in estuaries. Journal of Experimental Marine Biology and Ecology 416:243-253.

Machias A, Karakassis I, Giannoulaki M, Papadopoulou KN, Smith CJ, and Somarakis S. 2005. Response of demersal fish communities to the presence of fish farms. Marine EcologyProgress Series 288:241-250.

Machias A, Karakassis I, Labropoulou M, Somarakis S, Papadopoulou KN, and Papaconstantinou C. 2004. Changes in wild fish assemblages after the establishment of a fish farming zone in an oligotrophic marine ecosystem. Estuarine Coastal and Shelf Science 60:771-779.

McLean DL, Harvey ES, and Meeuwig JJ. 2011. Declines in the abundance of coral trout (Plectropomus leopardus) in areas closed to fishing at the Houtman Abrolhos Islands, Western Australia. Journal of Experimental Marine Biology and Ecology 406:71-78.

Ozgul A, and Angel D. 2013. Wild fish aggregations around fish farms in the Gulf of Aqaba, Red Sea: implications for fisheries management and conservation. Aquaculture Environment Interactions 4:135-145.

Papoutsoglou S, Costello MJ, Stamou E, and Tziha G. 1996. Environmental conditions at seacages, and ectoparasites on farmed European sea-bass, Dicentrarchus labrax (L.) and 
536

537

538

539

540

541

542

543

544

545

546

547

548

549

550

551

552

553

554

555

556

557

558

559

560

561

562

563

564

565

566

567

568

569

570

571

572

573

574

575

576

577

578

579

gilt-head sea-bream, Sparus aurata L., at two farms in Greece. Aquaculture Research 27:25-34.

Parsons Brinckerhoff, and SARDI. 2003. Upper Spencer Gulf: Technical Review for Aquaculture Management Plans - Phase 2. Prepared for PIRSA Aquaculture. Adelaide: Parsons Brinckerhoff.

Pearson TH, and Black KD. 2001. The environmental impacts of marine fish cage culture. In: Black KD, ed. Environmental Impacts of Aquaculture. Sheffield, England: Sheffield Academic Press, 1-31.

Pelc RA, Warner RR, Gaines SD, and Paris CB. 2010. Detecting larval export from marine reserves. Proceedings of the National Academy of Sciences of the United States of America 107:18266-18271.

Roberts CM, Bohnsack JA, Gell F, Hawkins JP, and Goodridge R. 2001. Effects of marine reserves on adjacent fisheries. Science 294:1920-1923.

Russ GR, and Alcala AC. 2011. Enhanced biodiversity beyond marine reserve boundaries: The cup spillith over. Ecological Applications 21:241-250.

Santana-Garcon J, Newman SJ, and Harvey ES. 2014. Development and validation of a midwater baited stereo-video technique for investigating pelagic fish assemblages. Journal of Experimental Marine Biology and Ecology 452:82-90.

Sara G. 2007a. Ecological effects of aquaculture on living and non-living suspended fractions of the water column: A meta-analysis. Water Research 41:3187-3200.

Sara G. 2007b. A meta-analysis on the ecological effects of aquaculture on the water column: Dissolved nutrients. Marine Environmental Research 63:390-408.

Shepherd SA. 1974. An underwater survey near Crag Point in upper Spencer Gulf. Adelaide: Department of Environment and Conservation.

Stobart B, Garcia-Charton JA, Espejo C, Rochel E, Goni R, Renones O, Herrero A, Crec'hriou R, Polti S, Marcos C, Planes S, and Perez-Ruzafa A. 2007. A baited underwater video technique to assess shallow-water Mediterranean fish assemblages: Methodological evaluation. Journal of Experimental Marine Biology and Ecology 345:158-174.

Tanner JE, and Fernandes M. 2010. Environmental effects of yellowtail kingfish aquaculture in South Australia. Aquaculture Environment Interactions 1:155-165.

Tuya F, Sanchez-Jerez P, Dempster T, Boyra A, and Haroun RJ. 2006. Changes in demersal wild fish aggregations beneath a sea-cage fish farm after the cessation of farming. Journal of Fish Biology 69:682-697.

Uglem I, Karlsen Ø, Sanchez-Jerez P, and Sæther BS. 2014. Impacts of wild fishes attracted to open-cage salmonid farms in Norway. Aquaculture Environment Interactions 6:91-103.

Unsworth RKF, Peters JR, McCloskey RM, and Hinder SL. 2014. Optimising stereo baited underwater video for sampling fish and invertebrates in temperate coastal habitats. Estuarine Coastal and Shelf Science 150:281-287.

Valle C, Bayle-Sempere JT, Dempster T, Sanchez-Jerez P, and Gimenez-Casalduero F. 2007. Temporal variability of wild fish assemblages associated with a sea-cage fish farm in the south-western Mediterranean Sea. Estuarine Coastal and Shelf Science 72:299-307.

Watson DL, Harvey ES, Anderson MJ, and Kendrick GA. 2005. A comparison of temperate reef fish assemblages recorded by three underwater stereo-video techniques. Marine Biology 148:415-425. 
580 Willis TJ, Millar RB, and Babcock RC. 2000. Detection of spatial variability in relative density of fishes: comparison of visual census, angling, and baited underwater video. Marine Ecology Progress Series 198:249-260.

584

Wraith J, Lynch T, Minchinton TE, Broad A, and Davis AR. 2013. Bait type affects fish assemblages and feeding guilds observed at baited remote underwater video stations. Marine Ecology Progress Series 477:189-199. 
1

Map of study location

Map showing the location of study sites within Spencer Gulf (black boxes = lease sites, open boxes $=$ control sites). Inset shows location of SpencerGulf. 


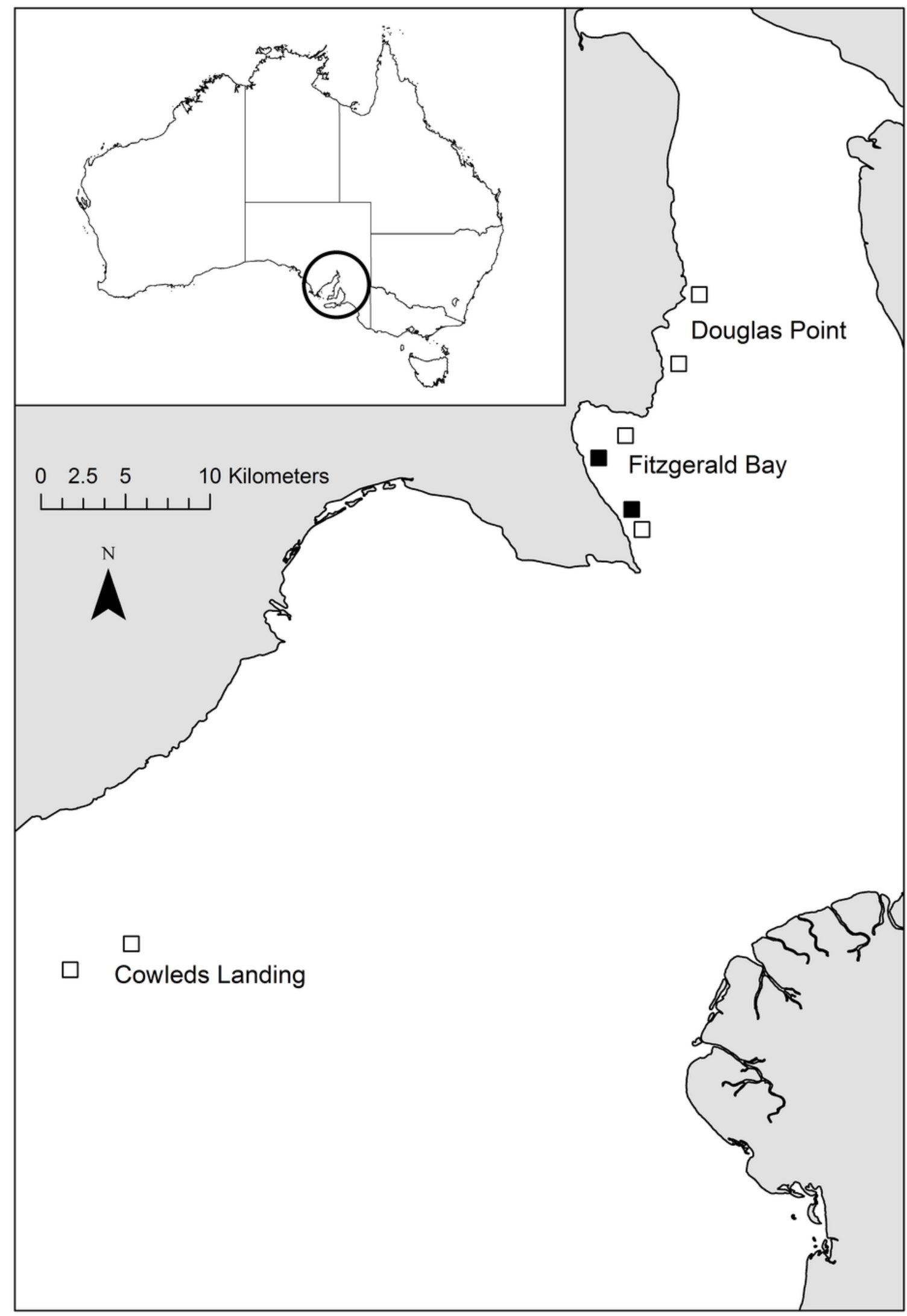


2

MDS plot of local effects of aquaculture

Non-metric multidimensional scaling plot showing the influence of Proximity to Aquaculture ( $\boldsymbol{\Lambda}=$ lease, $\boldsymbol{\nabla}=$ control) and Location (blue=north, green=south) on benthic fish and crustacean assemblages in Fitzgerald Bay (stress $=0.14$ ). Biplot shows correlations with key taxa ( $r>0.4$ labelled), with the circle scaled to $r=1$. 


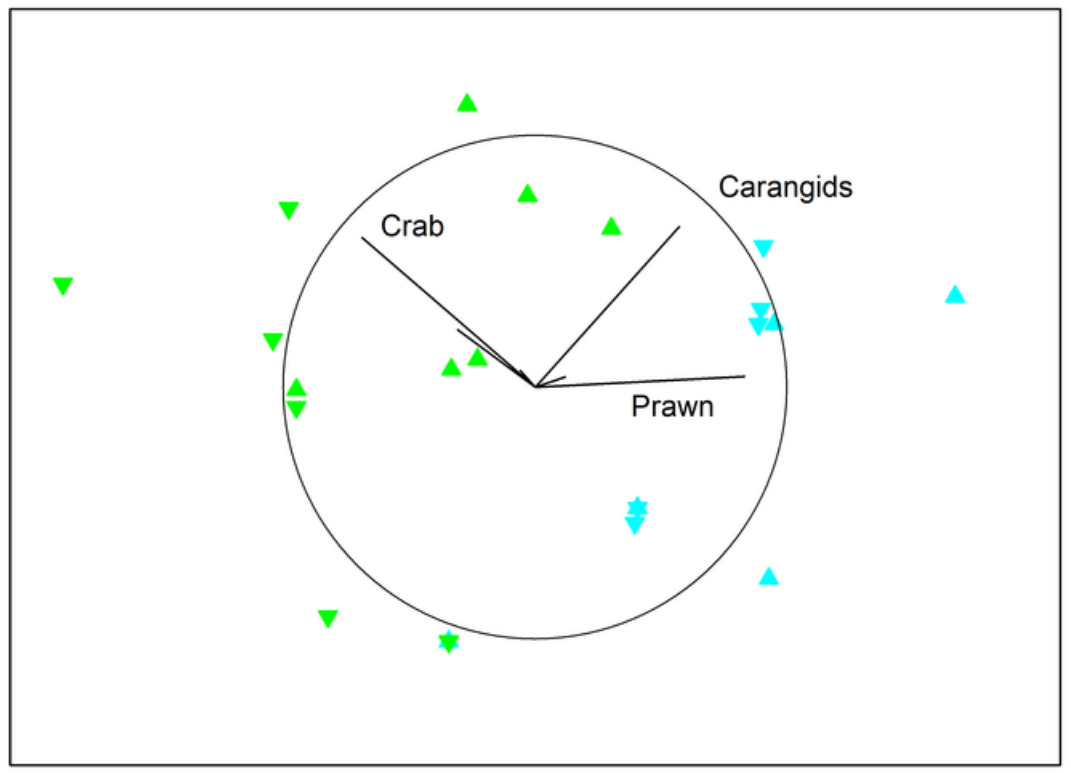




\section{Table $\mathbf{1}$ (on next page)}

Summary of taxa recorded during local effects survey

Taxa detected during study of local effects of aquaculture in Fitzgerald Bay. Data are means with standard error in brackets. 


\begin{tabular}{llrllrrr}
\hline Proximity & Location & Blue Crab & $\begin{array}{l}\text { Western } \\
\text { King } \\
\text { Prawn }\end{array}$ & Benthic & Carangid & $\begin{array}{l}\text { Port } \\
\text { Jackson } \\
\text { Shark }\end{array}$ & Snapper \\
\hline Control & North & 0 & $2.0(0.26)$ & $2.3(0.42)$ & $3.8(1.72)$ & 0 & $0.2(0.17)$ \\
Control & South & $1.5(0.50)$ & 0 & $2.7(0.88)$ & 0 & $0.3(0.21)$ & $0.8(0.83)$ \\
Lease & North & 0 & $1.3(0.49)$ & $1.2(0.40)$ & $2.7(2.29)$ & 0 & $1.7(1.67)$ \\
Lease & South & $2.5(0.22)$ & $1.3(0.61)$ & $3.7(0.33)$ & $3.5(2.43)$ & $0.3(0.21)$ & 0 \\
\hline
\end{tabular}


Table 2 (on next page)

Summary of taxa recorded during regional effects survey

Taxa detected during study of regional effects of aquaculture in Fitzgerald Bay. Data are means with standard error in brackets. 


\begin{tabular}{lrrrrrrr}
\hline Location & Site & Blue Crab & Benthic & Carangid & Snapper & Leatherjacket & Other \\
\hline \hline Cowleds Landing & 1 & 0 & $1.2(0.54)$ & 0 & 0 & 0 & $1.2(0.31)$ \\
Cowleds Landing & 2 & $0.2(0.17)$ & $1.0(0.26)$ & $1.8(1.47)$ & 0 & 0 & $1.3(0.56)$ \\
Fitzgerald Bay & 3 & 0 & $1.2(0.17)$ & $0.7(0.49)$ & 0 & 0 & 0 \\
Fitzgerald Bay & 4 & $3.0(0.63)$ & $1.7(0.42)$ & $0.2(0.17)$ & $1.0(0.52)$ & 0 & $0.5(0.22)$ \\
Point Douglas & 5 & $0.8(0.31)$ & $1.5(0.34)$ & 0 & $0.7(0.33)$ & $2.5(0.72)$ & $0.5(0.50)$ \\
Point Douglas & 6 & 0 & $0.7(0.33)$ & 0 & 0 & 0 & $0.5(0.22)$ \\
\hline
\end{tabular}


Table 3(on next page)

PERMANOVA table for bait effects

PERMANOVA table showing effects of Proximity to Aquaculture cages, Location within

Fitzgerald Bay and Bait Type on benthic fish and crustacean assemblages detected using BRUVs. 
1

\begin{tabular}{lrrrr}
\hline Source & df & \multicolumn{1}{c}{ SS } & Pseudo-F & P(perm) \\
\hline \hline Proximity & 1 & 4093.8 & 5.44 & $\mathbf{0 . 0 0 3 5}$ \\
Location & 1 & 4878.6 & 6.48 & $\mathbf{0 . 0 0 0 5}$ \\
Bait & 2 & 11220 & 7.45 & $\mathbf{0 . 0 0 0 1}$ \\
ProximityxLocation & 1 & 2898.8 & 3.85 & $\mathbf{0 . 0 1 8 4}$ \\
ProximityxBait & 2 & 3596.1 & 2.39 & $\mathbf{0 . 0 4 7 3}$ \\
LocationxBait & 2 & 3351.2 & 2.23 & 0.0637 \\
ProximityxLocationxBait & 2 & 3173.2 & 2.11 & 0.0779 \\
Residual & 42 & 31615 & & \\
\hline
\end{tabular}

2

3 
3

MDS of bait effects

Non-metric multidimensional scaling plot showing differences in benthic fish and crustacean assemblages with Proximity to Aquaculture ( $\boldsymbol{\Lambda}=$ lease, $\boldsymbol{\nabla}=$ control), Location (filled=north, hollow=south) and Bait Type (green=pellets, brown=sardines, blue=none) in Fitzgerald Bay (stress $=0.14)$. Biplot shows correlations with key taxa ( $r>0.4$ labelled), with the circle scaled to $r=1$. 


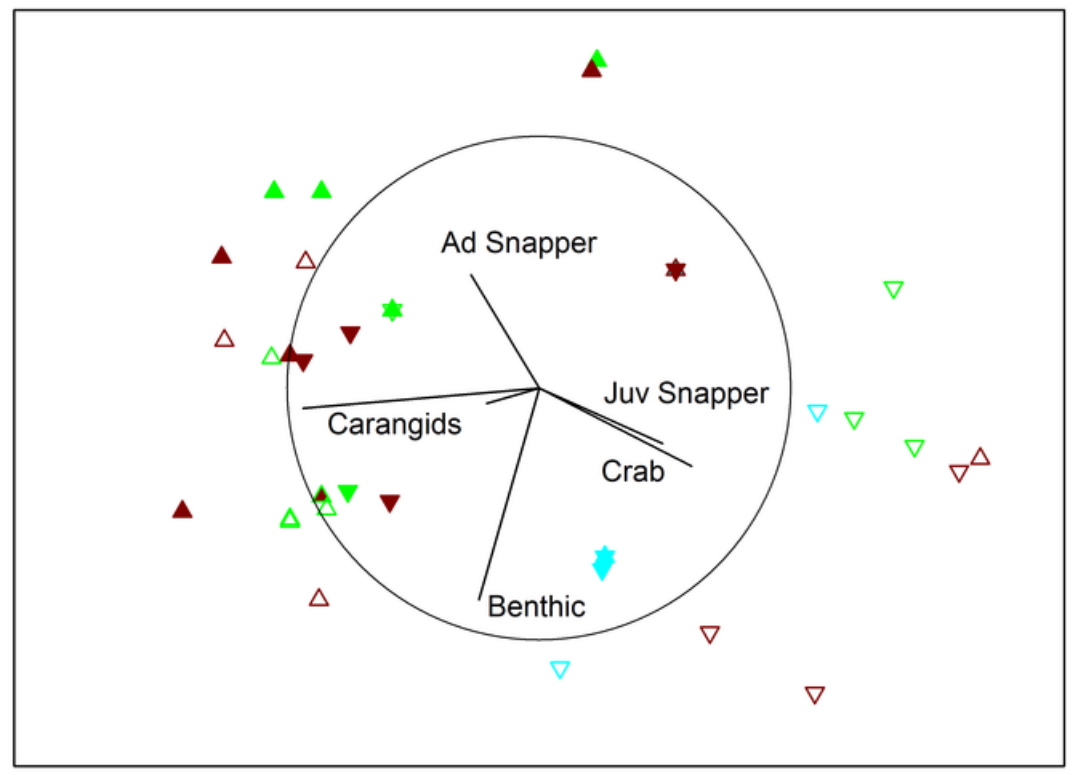




\section{Table 4 (on next page)}

Summary of taxa recorded during bait effects experiment

Taxa detected during study of bait effects on assemblages surveyed by BRUV in Fitzgerald Bay. Data are means with standard error in brackets. 


\begin{tabular}{lllrrrrrr}
\hline Proximity & Location & Bait & Blue crab & Benthic & Carangid & $\begin{array}{r}\text { Adult } \\
\text { snapper }\end{array}$ & $\begin{array}{r}\text { Juvenile } \\
\text { snapper }\end{array}$ & Leatherjacket \\
\hline \hline Control & North & Pellets & 0 & $0.4(0.24)$ & $7.0(4.36)$ & 0 & 0 & 0 \\
Control & North & None & 0 & $0.6(0.40)$ & 0 & 0 & 0 & 0 \\
Control & North & Sardine & 0 & $0.2(0.20)$ & $11.0(4.00)$ & 0 & 0 & 0 \\
Control & South & Pellets & $0.8(0.58)$ & $0.2(0.20)$ & $1.0(1.00)$ & 0 & $1.6(1.36)$ & 0 \\
Control & South & None & $0.3(0.33)$ & $0.7(0.33)$ & 0 & 0 & 0 & $0.3(0.33)$ \\
Control & South & Sardine & $2.7(0.33)$ & $0.7(0.33)$ & 0 & 0 & $4.0(3.06)$ & 0 \\
Lease & North & Pellets & 0 & $0.2(0.20)$ & $4.0(1.87)$ & $2.4(1.17)$ & 0 & 0 \\
Lease & North & None & 0 & $0.2(0.20)$ & 0 & 0 & 0 & 0 \\
Lease & North & Sardine & 0 & $0.6(0.40)$ & $30.0(10.00)$ & $1.4(0.75)$ & 0 & 0 \\
Lease & South & Pellets & 0 & $1.2(0.37)$ & $33.0(6.63)$ & 0 & 0 & 0 \\
Lease & South & None & 0 & 0 & 0 & 0 & 0 & 0 \\
Lease & South & Sardine & $0.4(0.40)$ & $0.6(0.60)$ & $9.0(4.58)$ & 0 & $1.2(0.97)$ & $0.4(0.24)$ \\
\hline
\end{tabular}


Table 5(on next page)

PERMANOVA of temporal differences

PERMANOVA table showing effects of Time, Proximity to Aquaculture cages, and Location within Fitzgerald Bay on benthic fish and crustacean assemblages detected using BRUVs. 


\begin{tabular}{lrrrr}
\hline Source & df & \multicolumn{1}{c}{ SS } & Pseudo-F & P(perm) \\
\hline Time & 2 & 11597 & 9.55 & $\mathbf{0 . 0 0 0 1}$ \\
Proximity & 1 & 1006.7 & 1.66 & 0.2284 \\
Location & 1 & 9867.1 & 16.25 & $\mathbf{0 . 0 0 0 1}$ \\
TimexProximity & 1 & 832.38 & 1.37 & 0.298 \\
TimexLocation & 2 & 2541 & 2.09 & 0.1045 \\
ProximityxLocation & 1 & 3157.5 & 5.20 & $\mathbf{0 . 0 0 9 8}$ \\
TimexProximityxLocation & 1 & 3147 & 5.18 & $\mathbf{0 . 0 0 6 9}$ \\
Residual & 44 & 26725 & & \\
\hline
\end{tabular}

2

3 
4

MDS of temporal effects

Non-metric multidimensional scaling plot showing differences in benthic fish and crustacean assemblages with Time (green=Time 1, brown=Time 2, blue=Time 3), Proximity to Aquaculture ( $\boldsymbol{\Lambda}=$ =lease, $\boldsymbol{\nabla}=$ control) and Location (filled=north, hollow=south) in Fitzgerald Bay (stress $=0.2$ ). Biplot shows correlations with key taxa ( $r>0.4$ labelled), with the circle scaled to $r=1$. 


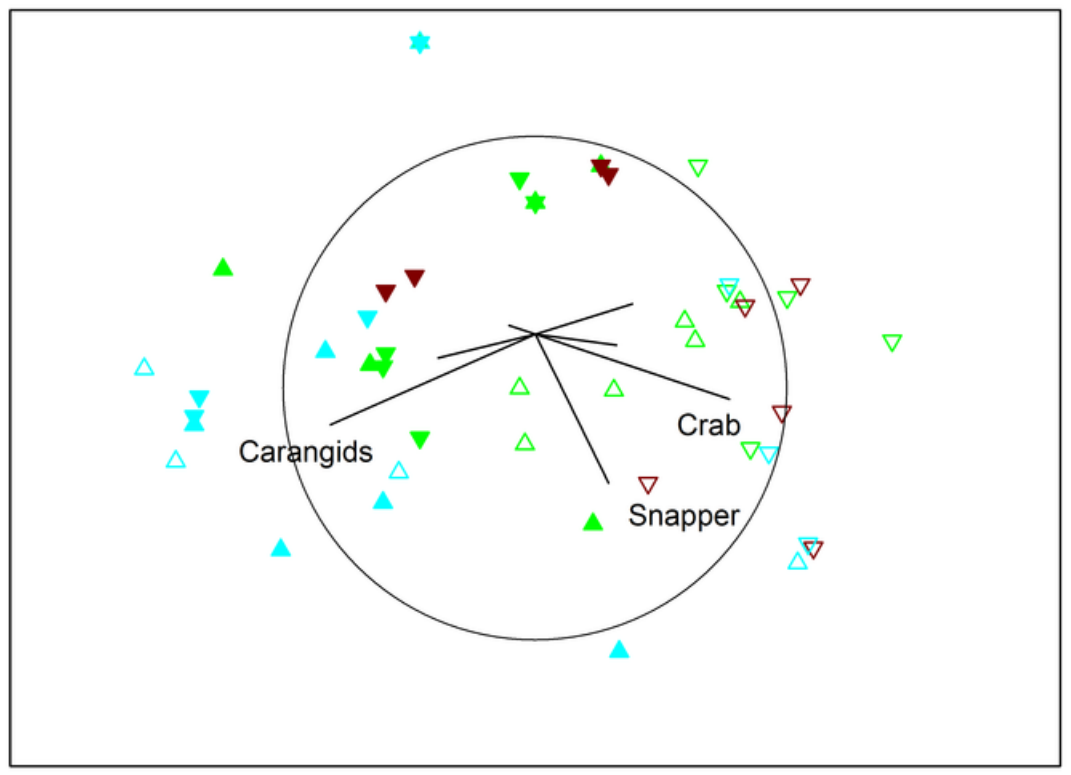

